\title{
Understanding potential conflicts between human and non-human-primates: a large-scale survey in Malaysia
}

\author{
Karimullah Karimullah ${ }^{1,2}$ - Anja Widdig ${ }^{1,3,4}$. Shahrul Anuar Mohd Sah ${ }^{2}$. \\ Federica Amici ${ }^{1,3}$ (i)
}

Received: 25 September 2020 / Revised: 17 January 2022 / Accepted: 25 January 2022 /

Published online: 1 March 2022

(c) The Author(s) 2022

\begin{abstract}
With increasing anthropogenic pressure, interactions between humans and wildlife may become more frequent, including conflictual ones. To reduce conflicts, it is important to understand how different factors (e.g. education, previous experience, demographic variables) interplay with each other and contribute to the emergence of negative attitudes and behaviours toward wildlife in humans. To address this issue, we conducted a large-scale questionnaire in Malaysia, focusing on potential conflicts between human and other primates. We used generalized linear mixed models to assess how formal education, knowledge about primates, negative experience and potential competition affected participants' negative attitudes to primates (i.e. how humans perceive primates), their behavioural intentions (i.e. opinion on how to reduce conflicts) and behaviour (i.e. measures taken to reduce negative interactions). We found that negative experience and potential competition had a negative impact on participants' attitude and behavior (i.e. primates were more likely perceived as filthy, as negatively affecting residents' health and safety, and as an increasing problem, with participants more likely to use invasive methods, including captures). Both higher education and better knowledge of primates predicted more positive behavioural intentions (i.e. primates should be protected, non-invasive interventions should be used). Higher education, however, was also linked to more negative attitudes (i.e. primates negatively affect residents' health and safety), and partly to negative behavior (e.g. use of invasive methods). In contrast, better knowledge about primates predicted positive behaviour (i.e. exclusive use of non-invasive methods). Therefore, although better knowledge of primates had no clear effect on human attitudes, it may impact on their decisions to reduce potential conflicts with wildlife, and might be the most powerful tool to mitigate conflicts between humans and other species.
\end{abstract}

Keywords Education $\cdot$ Attitude toward wildlife $\cdot$ Behavioural intentions $\cdot$ Environmental knowledge $\cdot$ Experience $\cdot$ Competition

Communicated by Karen E. Hodges.

Karimullah Karimullah and Federica Amici have contributed equally to this work.

Extended author information available on the last page of the article 


\section{Introduction}

Anthropogenic pressure has been steadily increasing in the last centuries, causing substantial changes to our planet (Sanderson et al. 2002; Waters et al. 2016). Through population growth, agricultural practices, increasing demand for resources, urbanization and other anthropogenic activities, humans have vastly contributed to a reduction in the functional and structural complexity of ecosystems (Smart et al. 2006; Junker et al. 2015; Steffen et al. 2015; Barnosky and Hadly 2016), while the frequency of human-wildlife interactions has steadily increased over the past years (Soulsbury and White 2015). The spectrum of human-wildlife interactions is large, spanning from positive interactions (like appreciation and reverence) to more negative and conflictual ones (including latent and mutual intolerance; see e.g. Humle and Hill 2016; Frank and Glikman 2019; Bhatia et al. 2020; Pooley et al. 2021). To date, research has mainly focused on the occurrence of negative interactions between humans and other species (Bhatia et al. 2020), because this allows researchers to better understand potential causes of conflict and possibly mitigate conflictual situations.

Conflicts between humans and wildlife, for instance, can arise when wildlife poses (or is perceived to pose) threats to human health, food or property (Conover 2002; Treves and Karanth 2003; Peterson et al. 2011; Nyhus 2016). On the one hand, human-wildlife conflicts might have a negative impact on human health, safety and welfare: humans may be injured or killed by wildlife, during attacks or accidents, or as a consequence of zoonotic disease transmission (Conover 2002; Nyhus 2016). Moreover, conflicts with wildlife can cause direct and indirect economic damage to human crops, livestock and property (Woodroffe et al. 2005; Linnell et al. 2010; Barua et al. 2013). On the other hand, human-wildlife interactions may have a negative impact on biodiversity and ecosystem health. Throughout history, for instance, humans have contributed to the reduction of wildlife habitat, the decline and extinction of many species, and ultimately to a decrease in biodiversity (Dirzo et al. 2014; Nyhus 2016; Surovell et al. 2016). Therefore, reducing potential conflicts between humans and wildlife, and mitigating their negative consequences, is a necessary goal for politics, science and society (Woodroffe et al. 2005; Reidinger and Miller 2013).

Increasing knowledge about wildlife (i.e. facts and information that people acquire about wildlife) can be a powerful tool to improve attitudes toward wildlife and mitigate potential conflicts with humans (Stern et al. 2014; Nyhus 2016; Ardoin et al. 2020). The acquisition of such knowledge can occur in many different settings, from more informal ones (e.g. specific activities by conservation organizations) to more formal ones (e.g. as part of school curricula, and/or within biology classes; see e.g. Braus and Wood 1993; Rickinson and Robinson 1999; Krsany 2020). By increasing humans' knowledge about wildlife and environment, for instance, formal education can improve human attitudes (i.e. how humans perceive wildlife) and behaviour (i.e. how humans interact with wildlife; see Ardoin et al. 2020). However, the link between these factors is highly controversial (West 2015; Marcinkowski and Reid 2019; Junker et al. 2020; Krsany 2020). For instance, other factors may serve as moderators in the relationship between attitude and behaviour, including previous experience, behavioural intentions (e.g. humans' opinion on how to reduce conflictual interactions) and other personal factors like age, gender or religion (Manstead 2001; Wallace et al. 2005; Steg and Vlek 2009; Marcinkowski and Reid 2019). To disentangle how these factors interplay and to understand their relative impact on the adoption 
of behavioural strategies that might reduce both human-wildlife conflicts and their negative consequences, more research is urgently needed (Marcinkowski and Reid 2019).

In this study, we aimed to assess the link between knowledge of wildlife, negative attitudes and behaviour toward wildlife, while accounting for the role played by participants' previous experience, behavioural intentions and other demographic factors. For this purpose, we conducted a large-scale questionnaire in Malaysia, focusing on potential conflicts between human and non-human primates (hereafter primates). Malaysia is one of the world's most biodiverse regions (Mittermeier et al. 2011), but has high rates of urbanization and deforestation (Achard et al. 2014; Stibig et al. 2014; Malaysian Department of Forestry 2016; Global Forest Watch 2018). This directly threatens the survival of many different species, including several primates (Margono et al. 2014; McCallum 2015), and strongly increases the potential of human-wildlife conflicts (Hassan et al. 2017; Goldthorpe and Neo 2011). In Malaysia, interactions between humans and primates are frequent. Malaysia is home to 25 primate species, 13 of which have been listed as Endangered or Critically Endangered (International Union for Conservation of Nature; IUCN 2020). Although all primates in Malaysia are protected by law and cannot be hunted or traded without a special license or permit (Malaysia 2010, Wildlife Conservation Act), law enforcement is largely insufficient (Lappan and Ruppert 2019). Moreover, primates are directly affected by the dramatic decline of forest habitat (IUCN 2020), and are often forced to forage in anthropogenic areas, increasing the probability of interactions with humans (Lappan and Ruppert 2019). Indeed, primates constitute the main source of conflicts with humans in Malaysia, with more than $70 \%$ of complaints to the authorities regarding primates and, especially, long-tailed macaques, Macaca fascicularis (Lappan and Ruppert 2019).

In this study, we provided participants with questionnaires assessing their knowledge of primates, their previous experience with primates, their negative attitudes and behavioural intentions toward primates (including possible approaches to reduce conflicts with humans), and their behaviour to primates (including measures taken by participants to reduce conflicts with them). We further collected demographic data to assess the role of formal education and possible competition with primates on participants' negative attitudes, behavioural intentions and behaviour. We especially focused on the negative aspects of the human-primate relationship (e.g. negative attitudes, negative experiences with primates), because these may be more relevant to understand the occurrence of conflictual situations between humans and other species (see Bhatia et al. 2020, for a discussion). In particular, we predicted that knowledge of primates would improve participants' attitude toward primates (Prediction 1a), their behavioural intentions (Prediction 1b) and their actual behaviour (Prediction 1c). Likewise, we predicted a negative effect of low formal education (Predictions 2a-2c), previous negative experience with primates (Predictions $3 a-3 c$ ) and potential competition over resources (Predictions 4a-4c) on participants' attitudes, behavioural intentions and behaviour, and a detrimental effect of negative attitudes on participants' behaviour toward primates (Prediction 5; see Table 1 for summary of predictions). 
Table 1 Predictions tested in this study, models run to test them, and whether the predictions were supported by our data

\begin{tabular}{|c|c|c|c|}
\hline Predictions & & Models & Support \\
\hline \multirow[t]{3}{*}{ 1. Knowledge of primates predicts better... } & a. Attitude & M1-M3 & No \\
\hline & b. Behavioural intentions & M4-M6 & Yes \\
\hline & c. Behaviour & M7-M9 & Yes \\
\hline \multirow[t]{3}{*}{ 2. Formal education predicts better... } & a. Attitude & M1-M3 & No \\
\hline & b. Behavioural intentions & M4-M6 & Yes \\
\hline & c. Behaviour & M7-M9 & No \\
\hline \multirow{3}{*}{$\begin{array}{l}\text { 3. Previous negative experience with primates predicts } \\
\text { worse... }\end{array}$} & a. Attitude & M1-M3 & Yes \\
\hline & b. Behavioural intentions & M4-M6 & No \\
\hline & c. Behaviour & M7-M9 & Yes \\
\hline \multirow{3}{*}{$\begin{array}{l}\text { 4. Potential competition with primates over food predicts } \\
\text { worse... }\end{array}$} & a. Attitude & M1-M3 & Yes \\
\hline & b. Behavioural intentions & M4-M6 & No \\
\hline & c. Behaviour & M7-M9 & Yes \\
\hline 5. Negative attitudes toward primates predict worse... & Behaviour & M7-M9 & No \\
\hline
\end{tabular}

\section{Methods}

\section{Ethical statement}

This study was approved by the ethical committee of the Universiti Sains Malaysia, which included both animal and human ethics experts. The study complied with the Declaration of Helsinki and the guidelines of the German Association of Professional Psychologists. Participation was voluntary and completely anonymous. Written informed consent was obtained from all subjects before testing started, and also for subjects under 18, from their parent and/or legal guardian. Participants were previously informed about the purpose of the study, about the fact that data would be confidential and completely anonymous, and they could interrupt their participation in the study at any time.

\section{Participants}

We conducted interviews from October 2018 to August 2019 with 553 participants: 294 females (mean age \pm SD: $33 \pm 13$ years) and 259 males (mean age \pm SD: $35 \pm 13$ years). Participants were recruited across 10 of the 13 Malaysian States among people having continuously resided in the country for at least 5 years (see Supplementary Material for more details). The first author (KK) made contact with local universities, colleges, schools, social or cultural centers, and looked for volunteers willing to help in data collection in the area. KK instructed volunteers and then accompanied them during data collection with at least 10 participants. If the volunteer could reliably collect data as explained (see below), KK left her/him the printed questionnaires to be distributed in the area. KK purposely travelled to both rural and urban areas all over Malaysia to recruit a representative sample of participants. Most participants resided in rural areas (74\%) and defined themselves as being Muslims (91\%), belonging to the ethnic group of Malays (94\%) and having 
completed secondary education (64\%). More details on the demographic characteristics of the participants are provided as Supplementary Material.

\section{Questionnaires}

All participants were approached by KK and/or volunteers, and were provided with four printed A4 pages in their native language (i.e. Malay). They were asked to complete the questionnaire alone, possibly in a quiet room, and hand it back to the first author when ready. Most participants decided to fill in the questionnaire on the spot, so that the first author and/or volunteers were present if participants had questions. Others filled it in later on, but were provided with the first author and/or volunteers' contact, in case they had questions. We distributed a total of 1000 questionnaires. Of these, 288 were never returned and 159 were returned damaged or empty, so that no data could be extracted from them. Therefore, the analyses of this study are based on the questionnaires of 553 participants.

The questionnaire consisted of six parts, containing: (1) demographic information (e.g. residence, age, gender, formal education of the participant) and other information to assess potential competition over resources (e.g. whether participants grow crops); (2) assessment of participants' specific knowledge of primates (e.g. recognition of and knowledge about Malaysian primate species, knowledge of the institutions responsible for dealing with primates in case of conflicts with humans); (3) assessment of previous negative experience with primates (e.g. damages caused by primates to participants or other acquaintances, or to their properties); (4) assessment of participants' negative attitudes to primates (e.g. whether primates were considered as filthy, as negatively affecting the safety and health of residents, or as an increasing problem); (5) assessment of participants' behavioural intentions (i.e. their opinion about possible approaches to reduce human-primate conflictual interactions); (6) assessment of participants' behaviour, including measures taken by participants to reduce negative interactions with primates (e.g. use of fences, dogs, alarms, noise, poison, stones, traps). We specifically focused on the negative aspects of the humanprimate relationship, to understand which factors contribute to the emergence of negative attitudes and behaviours toward primates in humans, and likely to the occurrence of conflictual situations. However, by focusing on the negative aspects of the human-primate relationship, our questions (i) might have enhanced participants' tendency to respond negatively with regards to their relation to primates, and (ii) might have failed to capture more positive aspects of this relation, which were not the focus of our work (see the Discussion).

\section{Statistical analyses}

We conducted analyses using generalized linear models (hereafter, GLMs; Baayen et al. 2008) with the glmmTMB package (version 1.0.1; Brooks et al. 2017) in R (R Core Team, version 3.5.0). A first set of models (M1-3) aimed to assess whether participants' negative attitudes to primates were predicted by their knowledge of primates, their formal education, potential competition with primates, and/or previous direct/indirect negative experience with them. As a measure of participants' negative attitudes to primates, we used three different binomial dependent (response) variables: whether participants agreed that primates (M1) are filthy and may thus contaminate the area of their house, (M2) negatively affect the safety and health of residents, or (M3) are an increasing problem. As test predictors, we included participants' knowledge of primates, level of formal education, competition with 
primates and previous negative experience with primates (see Supplementary Information for more details).

A second set of models (M4-6) assessed whether participants' behavioural intentions (including their opinion on how to reduce human-primate conflictual interactions) were predicted, as above, by their knowledge of primates, formal education, potential competition with primates, and/or previous negative experience with them. As a measure of participants' behavioural intentions, we used three different binomial dependent (response) variables: whether participants agreed that (M4) primates should be protected by law in their home ranges, (M5) authorities should reduce conflicts of humans with primates by controlling or relocating primate populations, or (M6) authorities should kill them. As test predictors, we included the aforementioned test predictors, as well as participants' institutional knowledge (i.e. whether participants knew the correct body/institution they had to refer to in case of conflicts with the primates; see Supplementary Information).

Finally, a last set of models (M7-9) assessed whether knowledge of primates, formal education, potential competition with primates, previous negative experience with them, and/or negative attitudes toward primates predicted participants' behaviour, and especially, the measures taken by participants to reduce negative interactions with primates. As a measure of participants' behaviour we used three different binomial dependent (response) variables: whether participants reported (M7) having ever caught primates, (M8) having used mild methods to reduce interactions with primates (i.e. fences, dogs, alarm systems, noise, or otherwise chasing primates without hurting them) or (M9) having used more invasive methods (i.e. stones, traps, poison or otherwise hunting them). As test predictors, we included participants' knowledge of primates, level of formal education, competition with primates, previous negative experience with primates, participants' institutional knowledge (as above), and negative attitudes to primates (i.e. whether primates were considered as filthy, as negatively affecting the safety and health of residents, or as an increasing problem; see Supplementary Information).

For all models, we further included participants' age, gender, residence (i.e. in a rural or urban area) and religion (i.e. belonging to the Muslim majority or not) as controls (Muthén 2002; Marcinkowski and Reid 2019). Continuous predictors such as age of participants were $z$-transformed to facilitate model convergence. No random effects were included, as data points were independent observations (i.e. different participants). All models had a binomial structure. We used likelihood ratio tests (Dobson et al. 2001) to compare full models containing all predictors with null models containing only control predictors. To rule out collinearity, we determined the VIFs (Field 2005), which were minimal (maximum VIFs across all models $=2.35$ ). Therefore, we could reliably interpret the effect of the single predictors included in our models. No convergence issues were detected.

\section{Results}

\section{Descriptive findings}

Most participants reported living in the same areas as long-tailed and pig-tailed macaques (Macaca nemestrina), and considered them as being the most destructive local primate species (Fig. 1a). Participants reporting crop raids by primates stated that on average $34 \%$ $( \pm 9 \%)$ of their crops were damaged, with primates spending an average of 24 min a week in the crop fields and raids usually including 6-10 individuals. Crop raiding occurred 

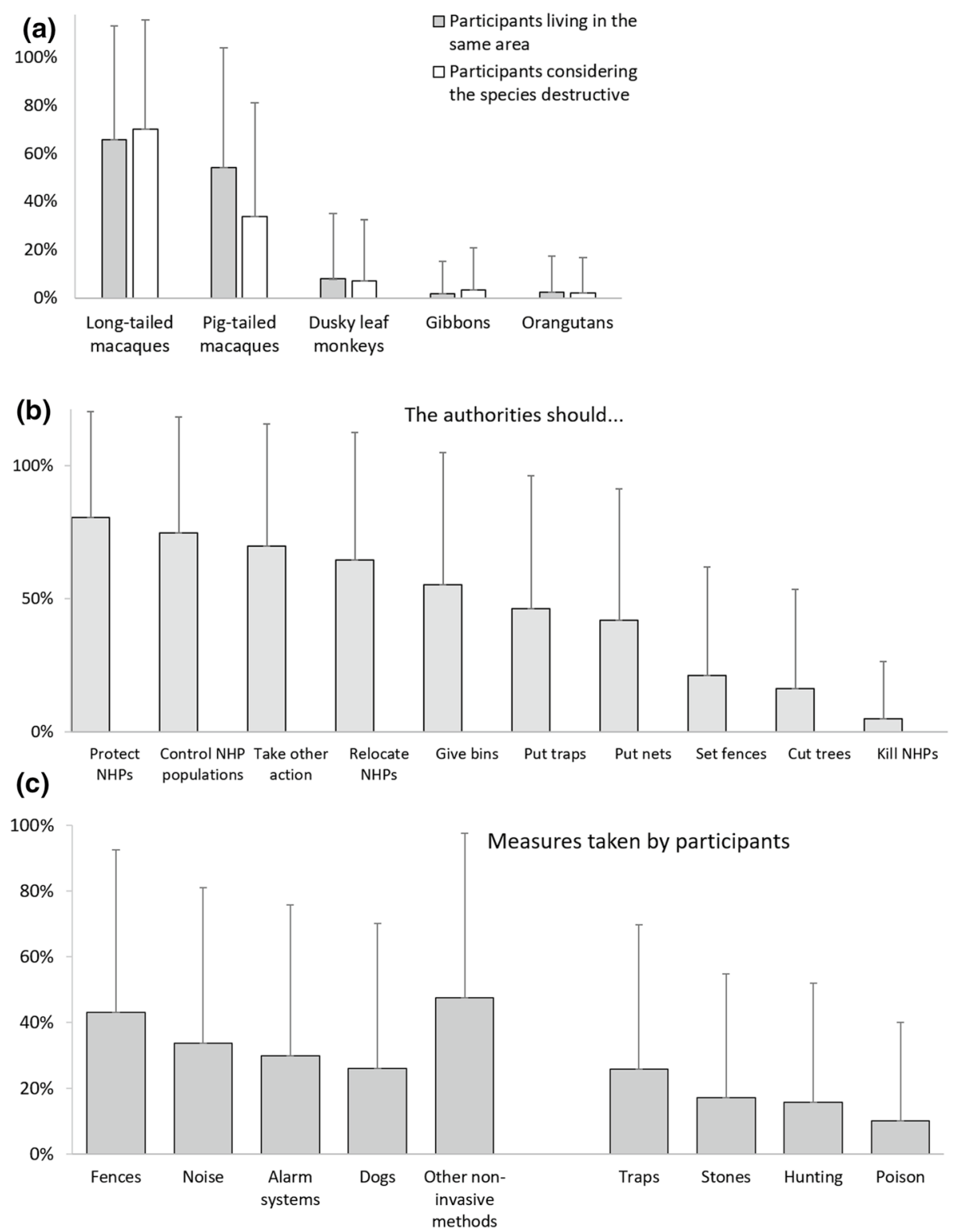

Fig. 1 a Attitude. For each non-human primate species, mean (+SD) percentage of participants reporting to live with that species (grey bars) and considering it destructive (white bars). b Behavioural intentions. Mean $(+\mathrm{SD})$ percentage of participants agreeing/strongly agreeing that the authorities should protect non-human primates (NHPs), control their populations, relocate them, provide residents with mechanical deterrents again primates (i.e. bins, traps, window nets, fences, cutting trees), kill primates or otherwise take other actions. c Behaviour. Mean (+SD) percentage of participants reporting a frequent/very frequent use of methods against non-human primates, either non-invasive (i.e. fences, noise, alarm systems, dogs or other methods not hurting the primates) or more invasive (i.e. traps, stones, hunting, poison) 
throughout the year, but mostly from May to July. Around 26\% of the participants reported having been disturbed by primates themselves, $15 \%$ having primates entering their house, $16 \%$ having been stolen food or other items from their homes by primates, $14 \%$ chased by primates and $8 \%$ bitten by primates. Similarly, $27 \%$ of the participants reported knowing somebody having been disturbed by primates, $18 \%$ having primates on the property, $16 \%$ having been stolen food or other items from their homes, $17 \%$ having been chased or $15 \%$ bitten by primates (see Fig. S2 in Supplementary Information). Only 32\% of the participants believed that hunting primates is illegal, although $62 \%$ of the participants believed that primates are otherwise protected.

The majority of participants (93\%) agreed/strongly agreed that primates should live in forests, and not in urban areas (see Fig. S3 in Supplementary Information). While most participants $(80 \%)$ agreed that primates should be protected by law, they also agreed/ strongly agreed that the authorities should take action to reduce human-primate conflicts, for instance, by controlling their population size, relocating them and placing mechanical defenses like fences to control primate populations (Fig. 1b). Few participants (27\%) knew that there are official institutions in place to refer to in case of human-primate conflict. Among the participants who stated that their crops had been raided by primates $(N=273)$, only $11 \%$ reported losses to official institutions. Participants reporting to the authorities $(\mathrm{N}=30)$ stated that the authorities took immediate action in three cases, translocated the monkeys in one case, and did not intervene in four cases. Participants relied more frequently on direct measures to prevent conflicts with primates, using mostly non-invasive methods (e.g. fences, noises, alarm systems), but also employing invasive ones (e.g. traps, stones, poison; Fig. 1c).

\section{Negative attitudes toward primates: the role of knowledge, formal education, competition with primates and previous experience (Models 1-3)}

For all models, the full model significantly differed from the corresponding null model (see Table 2). M1 showed that participants growing crops (hereafter, farmers), and those reporting experience of others (e.g., relatives, friends) being damaged by primates (hereafter, people with negative indirect experience), had a higher probability of considering primates as being filthy (as compared to non-farmers and participants with no negative indirect experience, respectively; both $\mathrm{p}<0.001$ ). In M2, participants with higher formal education $(\mathrm{p}=0.040)$, negative indirect experience $(\mathrm{p}=0.011)$, or directly competing with primates over food $(p=0.015)$, had a higher probability of considering primates as negatively affecting residents' health and safety. Moreover, M3 showed that farmers $(p=0.012)$, and those with negative indirect experience $(\mathrm{p}<0.001)$, had a higher probability of considering primates as an increasing problem. Therefore, competition with primates and previous negative experience with primates had a clear negative impact on participants' attitudes to primates. In contrast, higher formal education only increased the probability of considering primates as negatively affecting residents' health and safety (Table 1).

\section{Behavioural intentions and possible approaches to reduce human-primate conflicts: the role of knowledge, formal education, competition with primates and previous experience (Models 4-6)}

For M4 and M5 (but not M6), the full model significantly differed from the corresponding null model (see Table 3). In M4, participants with higher formal education and 


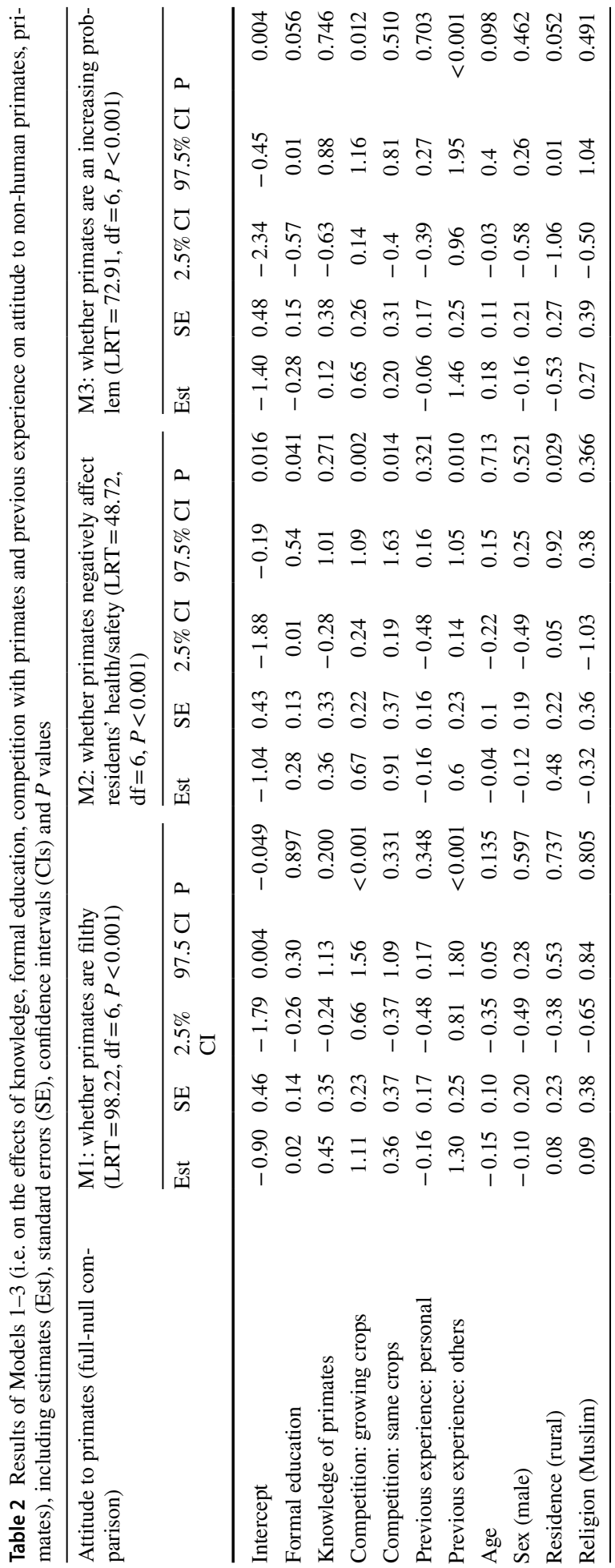




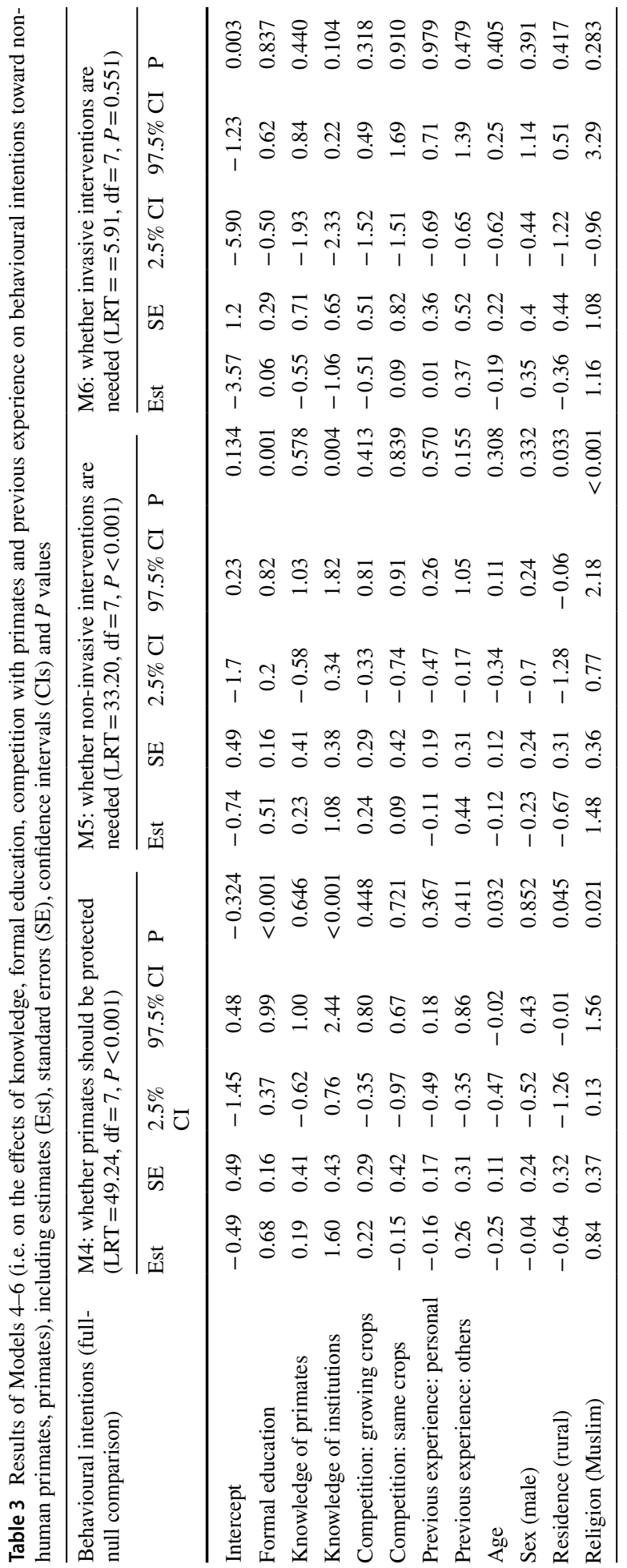


better knowledge of the institutions (both $\mathrm{p}<0.001$ ) were more likely to state that primates should be protected. Similarly, M5 showed that participants with higher formal education $(\mathrm{p}=0.001)$ and better institutional knowledge $(\mathrm{p}=0.004)$ were more likely to state that non-invasive interventions are needed. Therefore, higher formal education and better institutional knowledge had a clear positive impact on participants' behavioural intentions (Table 1).

\section{Behaviours and methods used to reduce conflict with primates: the role of knowledge, formal education, competition with primates, previous experience and negative attitudes to primates (Models 7-9)}

For all models, the full model differed significantly from the corresponding null model (see Table 4). In particular, M7 showed that farmers $(\mathrm{p}<0.001)$, participants with lower formal education $(p=0.046)$, those with negative indirect experience $(p=0.042)$ or believing that primates are filthy $(\mathrm{p}<0.001)$ were more likely to report having caught primates at least once. Considering primate as negatively affecting residents' health and safety instead, decreased the probability of participants having caught primates $(p=0.042)$. In M8, participants with higher formal education $(\mathrm{p}<0.001)$ and better primate knowledge $(p=0.013)$ were more likely to use non-invasive methods. Finally, M9 showed that farmers $(p=0.012)$, participants with lower institutional knowledge $(\mathrm{p}=0.047)$, but also participants with higher formal education $(\mathrm{p}=0.007)$ were more likely to use invasive methods. Therefore, competition with primates and previous conflicting experience negatively impacted on participants' behaviour, while better primate and institutional knowledge both had a clear positive impact on participants' behavior. In contrast, the role of formal education and negative attitude toward primates were less univocal (Table 1).

\section{Discussion}

In this study, we assessed how knowledge about primates, formal education, previous negative experience and potential competition with primates affected participants' negative attitudes to primates, their behavioural intentions and, in turn, their behaviour (Table 1). Our results showed that previous negative experience and potential competition had a clear negative impact on participants' attitudes and behavior. Moreover, whereas higher formal education mainly predicted better behavioural intentions toward primates, specific knowledge was linked to better behavioural intentions and also to better behaviour toward primates.

As expected, participants with more knowledge about primates and higher formal education also had better behavioural intentions (Predictions $1 \mathrm{~b}$ and $2 \mathrm{~b}$ ) and partially a more positive behaviour toward primates (Predictions 1c and partially 2c): participants expected authorities to protect primates and to use non-invasive measures to prevent/reduce conflictual interactions with primates, and in the case of having knowledge about primates, they were also more likely to take non-invasive measures in case of conflict. These results are in line with abundant literature showing a link between environmental education (both in formal and informal settings) and the emergence of better behavioural intentions and behaviour (see Ardoin et al. 2020; Krsany 2020). However, participants with more knowledge about primates and higher formal education did not have better attitudes (in contrast to Predictions 1a and 2a; but see Krsany 2020). Participants with higher formal education, for instance, were more likely to consider primates as a problem for the safety and health of 


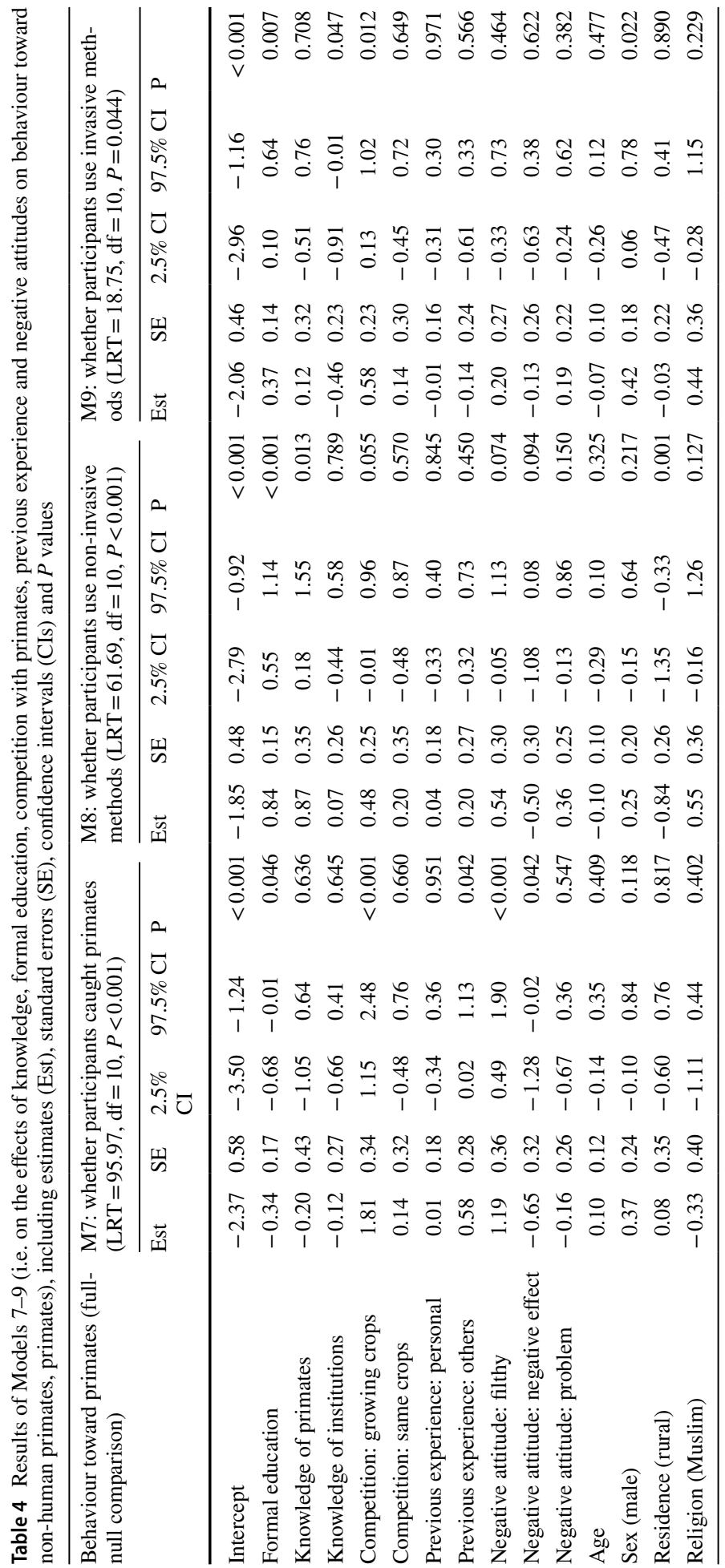


residents (M2), besides reporting the frequent use of both invasive (M9) and non-invasive methods (M8) to reduce conflicts with primates. However, participants with higher formal education were also more likely to state that they had never caught primates (M7), and that the authorities should protect primates (M4) and use non-invasive methods (M5) to reduce conflicts, suggesting a non-univocal role of formal education. In contrast, participants with more primate knowledge did not have better attitudes (M1-M3), but consistently reported using non-invasive methods (M8-M9), stated that the authorities should protect primates (M4) and use non-invasive methods to reduce conflicts (M5). These results suggest that specific knowledge about primates may have a stronger positive effect than formal education on participants' behaviour and behavioural intentions. These findings are in line with other studies questioning the link between (some kinds of) knowledge and better behaviours and behavioural intentions. Zhang et al. (2008), for instance, investigated people's wildlife consumption in South-West China, and found that participants' higher educational levels were not linked to better attitudes. Therefore, the authors suggested that generally improving education may not always be an effective measure to mitigate conflicts with wildlife (Zhang et al. 2008). Moreover, not all kinds of knowledge may be equally effective: if knowing the consequences of one's own behaviours may effectively increase conservation awareness and improve people's behaviours, more general systemic knowledge may have significantly less impact (Frick et al., 2004). Therefore, our results confirm the importance of implementing specific educational programs that provide detailed information on the target species (e.g. Frick et al. 2004; Zhang et al. 2008; see Krsany 2020).

As predicted, both negative experience and competition with primates had a negative impact on participants' attitude toward primates (Predictions 3a and 4a) and on their behaviour (Predictions $3 \mathrm{c}$ and $4 \mathrm{c}$ ), but not on their behavioural intentions (in contrast to Predictions $3 \mathrm{~b}$ and $4 \mathrm{~b}$; see Table 1). In particular, knowing other people who had been negatively affected by primates increased the probability of considering primates as filthy (M1), as an increasing problem (M2), and as negatively impacting the safety and health of residents (M3). Moreover, participants with previous negative experience were more likely to report having caught primates at least once (M7). Similarly, farmers were more likely to describe primates as filthy (M1) and as an increasing problem (M2), and when they directly competed with primates over the same food sources (i.e. growing the same crops that primates were thought of feeding on), they were also more likely to consider them as a problem for the safety and health of residents (M3), although it is possible that other species were indeed (also) feeding on the crops (see e.g. Holzner et al. 2019, about macaques actually having a positive impact on oil palm plantation, as biological pest control). Moreover, farmers reported the frequent use of invasive methods (M9), and more likely reported to have caught primates at least once (M7). This is in line with other literature suggesting that competition over resources may increase the conflict between humans and other species (see Humle and Hill 2016).

In contrast to our expectations, attitude to primates had no significant effect on whether participants took invasive or non-invasive methods to reduce conflicts, although it predicted whether participants reported having ever caught primates (partially in line with Prediction 5). In particular, participants considering primates as filthy were more likely to have previously caught primates at least once (M7), while those considering primates as negatively affecting residents' safety and health were less likely to have ever caught primates (M7). While these results might seem counter-intuitive, they are not: correctly perceiving primates as a potential health problem implies that people reduce contact with them, and thus might more rarely catch them. Furthermore, our study showed that long-tailed and pig-tailed macaques were considered the most destructive species, with participants often 
reporting damages to people and properties. This is in line with previous studies, showing that macaques are often considered a problem for humans and their properties (Nahallage et al. 2008; Campbell-Smith et al. 2010; Dittus et al. 2019), despite their potential of being essential to increase sustainable plantation management and maintain biodiversity (Holzner et al. 2019). Primates were considered a problem by residents in both urban and rural areas. This is not surprising, as interactions with macaques have become more frequent in Malaysian settlements, especially in areas with higher population growth (Perhilitan 2004; Hambali et al. 2012), where macaques are relatively abundant and can have increased access to anthropogenic food resources (Oro et al. 2013). Participants often reported that primates damaged people and properties, in line with other studies on macaques in Southeast Asia (Sha et al. 2009; Hambali et al. 2012).

As in other studies, the largest majority of participants agreed on the need to protect primates (Sha et al. 2009), but also required some form of intervention by the authorities, be it relocation, population control or distribution of mechanical deterrents (Sha et al. 2009; Campbell-Smith et al. 2010; Dittus et al. 2019). In line with other studies, participants reported using both invasive and non-invasive measures to reduce conflicts with primates, but only rarely referred to the authorities in case of conflict, as the authorities were often considered ineffective to face the problem (Campbell-Smith et al. 2010; Hassan et al. 2017; Dittus et al. 2019). This is noteworthy, as all primate species are protected by the Department of Wildlife and National Park, as they can be either hunted, kept or traded with a specific license/permission issued by the responsible authorities, or depending on the area they can never be hunted (see Malaysia 2010; Wildlife Conservation Act). Likely, this may largely depend on law enforcement being possibly insufficient in Malaysia, mostly because of lack of funds and human resources (Lappan and Ruppert 2019).

Our study has several important limitations. First, as most questionnaire-based studies, it relies on self-reported assessments that are necessarily subjective. In the future, more objective evaluations (e.g. assessing the real impact of primates through the use of camera traps) should be ideally combined with questionnaires to provide a more reliable assessment. Second, this study focused on the negative aspects of the relationship between humans and primates (e.g. negative experience, negative attitudes). This was necessary to better disentangle the relationship between human attitudes, behavioural intentions and behaviours in conflictual situations, as negative attitudes and experiences are more likely to contribute to the occurrence of conflictual situations. However, this choice might have led participants to only or more strongly focus on the negative aspects of their relationship to primates, although other positive aspects might have also been present. By negatively framing most of our questions, therefore, we might have biased participants to report more negative experiences, attitudes, behaviours and/or behavioural intentions. Even if this is true, and absolute frequencies in our study should thus be taken with some caution, the relation between variables is unlikely to be substantially affected by these biases. Our models, for instance, showed that negative attitudes toward primates were more likely when participants had previous negative experiences with primates, or potentially competed with primates over food. Even though our questions might have generally biased participant to report more negative attitudes toward primates, it is unlikely that they selectively biased specific groups of participants to report more negative attitudes (e.g. only participants with previous negative experience and potentially competing over resources with primates were biased by our focus on the negative aspects of the human-primate relationship, more likely reporting negative attitudes toward primates and therefore leading to a spurious significant link between negative attitudes, previous experience and potential competition). In the future, however, it would be interesting to investigate other and more positive aspects of 
the mutual and complex relationship between humans and other species, to also assess how positive attitudes interplay with negative ones in predicting behaviour toward wildlife.

Overall, our results support previous studies suggesting that the most effective way to improve human behaviour in potentially conflictual situations is to increase people's specific knowledge about primates and the responsible institutions, while decreasing negative experience and potential competition (Marcinkowski and Reid 2019). Direct specific knowledge (rather than general formal education) may not improve attitude toward primates, but it clearly impacts on the decisions taken by humans to reduce conflicts with wildlife. Hopefully, these findings will be useful to the authorities to further implement measures to reduce potential conflicts between humans and other primates. In the future, the authorities should consider providing further support to the residents by supporting environmental education projects providing more information (1) on primates, (2) on the institutional support available in case of conflict with primates, and (3) on the health risks associated with interactions with primates. Primates are a crucial component of different ecosystems (Hawes and Peres 2014; Estrada et al. 2017). With the decline of biodiversity, we are risking to lose primate diversity, and with that our closest living ancestors. For more than five million years, humans and primates have largely shared the same environments (Humle and Hill 2016), and primates are still an essential model for the study of human evolution. Moreover, primates have a strong impact on human communities, and can provide us with unique social, biological and economic benefits (see e.g. Holzner et al. 2019). To date, primates have been the focus of a lot of behavioural and cognitive research, but little is still known on the effectiveness of conservation strategies, including educational programs (Junker et al. 2020). Understanding which measures are most effective at improving human behaviour toward primates and decreasing conflicts will be a crucial endeavor in any conservation agenda to ensure the welfare and long-term survival of wild primate populations.

Supplementary Information The online version contains supplementary material available at https://doi. org/10.1007/s10531-022-02386-w.

Acknowledgements The first and last authors were generously supported by a research grant from the German Research Foundation (DFG) to the first author (AM 409/4-1). We are extremely grateful to the DFG for providing specific support to refugees, and to the University of Leipzig and the Max-Planck Institute for Evolutionary Anthropology for substantial help during this study. We are also grateful to the Editor Karen E. Hodges, for her extensive support, and to the anonymous reviewers, who provided detailed and constructive feedback.

Author contributions FA designed the study with input by KK and AW. KK collected and entered the data, with help by SAMS. FA conducted the statistical analyses and wrote the paper, with feedback from the other co-authors.

Funding Open Access funding enabled and organized by Projekt DEAL. German Research Foundation (AM 409/4-1).

Data availability Data is provided as Supplementary Material.

\section{Declarations}

Conflict of interest The authors declare no conflict of interest and no competing interest.

Ethical approval This study was approved by the ethical committee of the Universiti Sains Malaysia. The study complied with the Declaration of Helsinki and the guidelines of the German Association of Professional Psychologists. Participation was voluntary and completely anonymous. 
Informed consent Informed consent was obtained from all subjects before testing started, and also for subjects under 18, from their parent and/or legal guardian. Participants were previously informed about the purpose of the study, about the fact that data would be confidential and completely anonymous, and they could interrupt their participation in the study at any time.

Consent to participate It was collected for all participants by the first author.

Consent for publication It was collected for all participants by the first author.

Open Access This article is licensed under a Creative Commons Attribution 4.0 International License, which permits use, sharing, adaptation, distribution and reproduction in any medium or format, as long as you give appropriate credit to the original author(s) and the source, provide a link to the Creative Commons licence, and indicate if changes were made. The images or other third party material in this article are included in the article's Creative Commons licence, unless indicated otherwise in a credit line to the material. If material is not included in the article's Creative Commons licence and your intended use is not permitted by statutory regulation or exceeds the permitted use, you will need to obtain permission directly from the copyright holder. To view a copy of this licence, visit http://creativecommons.org/licenses/by/4.0/.

\section{References}

Achard F, Beuchle R, Mayaux P, Stibig HJ, Bodart C, Brink A, Lupi A (2014) Determination of tropical deforestation rates and related carbon losses from 1990 to 2010. Glob Change Biol 20:2540-2554

Ardoin NM et al (2020) Environmental education outcomes for conservation: a systematic review. Biol Conserv 241(108224):1-13

Baayen RH, Davidson DJ, Bates DM (2008) Mixed-effects modeling with crossed random effects for subjects and items. J Mem Lang 59(4):390-412

Barnosky AD, Hadly EA (2016) Tipping point for planet earth: how close are we to the edge? Thomas Dunne Books, New York

Barua M, Bhagwat SA, Jadhav S (2013) The hidden dimensions of human-wildlife conflict: health impacts, opportunity and transaction costs. Biol Conserv 157:309-316

Bhatia S, Redpath SM, Suryawanshi K, Mishra C (2020) Beyond conflict: exploring the spectrum of human-wildlife interactions and their underlying mechanisms. Oryx 54(5):621-628

Braus J, Wood D (1993) Environmental education in the schools: creating a program that works. Peace Corps, Washington, DC

Brooks ME, Kristensen K, van Benthem KJ, Magnusson A, Berg CW, Nielsen A, Bolker BM (2017) glmmTMB balances speed and flexibility among packages for zero-inflated generalized linear mixed modeling. R J 9(2):378-400

Campbell-Smith G, Simanjorang HV, Leader-Williams N, Linkie M (2010) Local attitudes and perceptions toward crop-raiding by orangutans (Pongo abelii) and other nonhuman primates in northern Sumatra, Indonesia. Am J Primatol 72(10):866-876

Conover MR (2002) Resolving human-wildlife conflicts: the science of wildlife damage management. CRC Press, Boca Raton

Dirzo R, Young HS, Galetti M, Ceballos G, Isaac NJ, Collen B (2014) Defaunation in the anthropocene. Science 345(6195):401-406

Dittus WP, Gunathilake S, Felder M (2019) Assessing public perceptions and solutions to human-monkey conflict from 50 years in Sri Lanka. Folia Primatol 90(2):89-108

Dobson A, Zidek J, Lindsey J (2001) An introduction to generalized linear models, 2nd edn. Chapman and Hall/CRC, Boca Raton

Estrada A, Garber PA, Rylands AB, Roos C, Fernandez-Duque E, Di Fiore A, Rovero F (2017) Impending extinction crisis of the world's primates: why primates matter. Sci Adv 3(1):e1600946

Field A (2005) Discovering statistics using SPSS. Saga Publication Ltd, London

Frank BE, Glikman JA (2019) Human-wildlife conflicts and the need to include coexistence. In: Frank BE, Glikman JA, Marchini S (eds) Human-wildlife interactions: turning conflict into coexistence. Cambridge University Press, Cambridge, pp 1-9

Frick J, Kaiser F, Wilson M (2004) Environmental knowledge and conservation behavior: exploring prevalence and structure in a representative sample. Pers Individ Diff 37:1597-1613 
Global Forest Watch Indonesia (2018) http://www.globalforestwatch.org/country/IDN/20. Accessed 9 Nov 2021

Goldthorpe G, Neo SH (2011) A preliminary investigation into the effects of hunting on three large ungulate species in Peninsular Malaysia, with implications for tiger conservation. Malay Nat $\mathbf{J}$ 63(3):549-560

Hambali K, Ismail A, Zulkifli SZ (2012) Human-macaque conflict and pest behaviors of long-tailed macaques (Macaca fascicularis) in Kuala Selangor Nature Park. Trop Nat Hist 12(2):189-205

Hassan S, Hambali K, Shaharuddin WYW, Amir A (2017) Human-wildlife conflict: a study of local perceptions in Jeli, Kelantan, Malaysia. Malay Nat J 69(2):113-125

Hawes JE, Peres CA (2014) Ecological correlates of trophic status and frugivory in neotropical primates. Oikos 123(3):365-377

Holzner A, Ruppert N, Swat F, Schmidt M, Weiß BM, Villa G, Widdig A (2019) Macaques can contribute to greener practices in oil palm plantations when used as biological pest control. Curr Biol 29(20):R1066-R1067

Humle T, Hill C (2016) People-primate interactions: implications for primate conservation. In: Wich SA, Marshall AJ (eds) An introduction to primate conservation. Oxford University Press, Oxford

IUCN Red List of Threatened Species (2020) e.T39758A17970536. UK.2020-2.RLTS T39758A17970536.en. https://doi.org/10.2305/IUCN

Junker J, Boesch C, Mundry R, Stephens C, Lormie M, Tweh C, Kühl HS (2015) Education and access to fish but not economic development predict chimpanzee and mammal occurrence in West Africa. Biol Conserv 182:27-35

Junker J, Petrovan SO, Arroyo-RodrÍguez V, Boonratana R, Byler D, Chapman CA, Cowlishaw G (2020) A severe lack of evidence limits effective conservation of the world's primates. Bioscience 70:1-10

Krsany ME (2020) Advancing environmental education practice. Cornell University Press, London

Lappan S, Ruppert N (2019) Primate research and conservation in Malaysia. Primates 34:35

Linnell JDC, Rondeau D, Reed DH, Williams R, Altwegg R, Raxworthy CJ, Gordon IJ (2010) Confronting the costs and conflicts associated with biodiversity. Anim Conserv 13(5):429-431

Malaysia LO (2010) Wildlife Conservation Act. Government of Malaysia, Kuala Lumbur

Malaysian Department of Forestry (2016) Forestry statistics. Malaysian Department of Forestry, Berlin

Manstead ASR (2001) Attitudes and behaviour. In: Smelser NJ, Baltes PB (eds) International encyclopedia of the social and behavioral sciences. Elsevier, Amsterdam

Marcinkowski T, Reid A (2019) Reviews of research on the attitude-behavior relationship and their implications for future environmental education research. Environ Educ Res 25(4):459-471

Margono BA, Potapov PV, Turubanova S, Stolle F, Hansen MC (2014) Primary forest cover loss in Indonesia over 2000-2012. Nat Clim Change 4(8):730-735

McCallum ML (2015) Vertebrate biodiversity losses point to a sixth mass extinction. Biodivers Conserv 24(10):2497-2519

Mittermeier RA, Turner WR, Larsen FW, Brooks TM, Gascon C (2011) Global biodiversity conservation: the critical role of hotspots. Biodiversity Hotspots. Springer, Berlin, pp 3-22

Muthén BO (2002) Beyond SEM: general latent variable modeling. Behaviormetrika 29(1):81-117

Nahallage CAD, Huffman MA, Kuruppu N, Weerasingha T (2008) Diurnal primates in Sri Lanka and people's perception of them. Primate Conserv 23:81-87

Nyhus PJ (2016) Human-wildlife conflict and coexistence. Annu Rev Environ Resour 41:143-171

Oro D, Genovart M, Tavecchia G, Fowler MS, Martínez-Abraín A (2013) Ecological and evolutionary implications of food subsidies from humans. Ecol Lett 16:1501-1514

Perhilitan (2004) Annual Report 67-68

Peterson MN, Birckhead JL, Leong K, Peterson MJ, Peterson TR (2011) Rearticulating the myth of humanwildlife conflict. Conserv Lett 3:74-82

Pooley S, Bhatia S, Vasava A (2021) Rethinking the study of human-wildlife coexistence. Conserv Biol 35(3):784-793

Reidinger RF Jr, Miller JE (2013) Wildlife damage management: prevention, problem solving, and conflict resolution. Johns Hopkins University Press, Baltimore

Rickinson M, Robinson L (1999) Environmental education research in the classroom: a shared methodological reflection by the teacher and the researcher. Environ Educ Res 5(1):77-94

Sanderson EW, Jaiteh M, Levy MA, Redford KH, Wannebo AV, Woolmer G (2002) The human footprint and the last of the wild. Bioscience 52:891-904

Sha JCM, Gumert MD, Lee BPH, Jones-Engel L, Chan S, Fuentes A (2009) Macaque-human interactions and the societal perceptions of macaques in Singapore. Am J Primatol 71(10):825-839

Smart SM, Thompson K, Marrs RH, Le Duc MG, Maskell LC, Firbank LG (2006) Biotic homogenization and changes in species diversity across humanmodified ecosystems. Proc R Soc Lond 273:2659-2665 
Soulsbury CD, White PCL (2015) Human-wildlife interactions in urban areas: a review of conflicts, benefits and opportunities. In: Taylor A, White P (eds) Wildlife research: interactions between humans and wildlife in urban areas. CSIRO, Canberra, pp 541-553

Steffen W, Broadgate W, Deutsch L, Gaffney O, Ludwig C (2015) The trajectory of the Anthropocene: the great acceleration. Anthr Rev 2(1):81-98

Steg L, Vlek CAJ (2009) Encouraging pro-environmental behaviour: an integrative review and research agenda. J Environ Psychol 29(3):309-317

Stern MJ, Powell RB, Hill D (2014) Environmental education program evaluation in the new millennium: what do we measure and what have we learned? Environ Educ Res 20(5):581-611

Stibig HJ, Achard F, Carboni S, Rasi R, Miettinen J (2014) Change in tropical forest cover of Southeast Asia from 1990 to 2010. Biogeosciences 11(2):247-258

Surovell TA, Pelton SR, Anderson-Sprecher R, Myers AD (2016) Test of Martin's overkill hypothesis using radiocarbon dates on extinct megafauna. Proc Natl Acad Sci 113:886-891

Treves A, Karanth KU (2003) Human-carnivore conflict and perspectives on carnivore management worldwide. Biol Conserv 17:1491-1499

Wallace DS, Paulson RM, Lord CG, Bond CF (2005) Which behaviors do attitudes predict? Metaanalyzing the effects of social pressure and perceived difficulty. Rev Gen Psychol 9(3):214-227

Waters CN, Zalasiewicz J, Summerhayes C, Barnosky AD, Poirier C, Gałuszka A, Jeandel C (2016) The Anthropocene is functionally and stratigraphically distinct from the Holocene. Science 351(6269):1-26

West SE (2015) Understanding participant and practitioner outcomes of environmental education. Environ Educ Res 21(1):45-60

Woodroffe R, Thirgood S, Rabinowitz A (2005) People and wildlife: conflict or coexistence? Cambridge University Press, Cambridge

Zhang L, Hua N, Sun S (2008) Wildlife trade, consumption and conservation awareness in southwest China. Biodivers Conserv 17:1493-1516

Publisher's Note Springer Nature remains neutral with regard to jurisdictional claims in published maps and institutional affiliations.

\section{Authors and Affiliations}

\section{Karimullah Karimullah ${ }^{1,2} \cdot$ Anja Widdig ${ }^{1,3,4} \cdot$ Shahrul Anuar Mohd Sah ${ }^{2}$. Federica Amici ${ }^{1,3}$ (D)}

\section{Federica Amici}

amici@eva.mpg.de

1 Behavioral Ecology Research Group, Faculty of Life Science, Institute of Biology, University of Leipzig, Leipzig, Germany

2 School of Biological Sciences, Universiti Sains Malaysia, Pulau Pinang, Malaysia

3 Research Group Primate Behavioural Ecology, Department of Human Behavior, Ecology and Culture, Max-Planck Institute for Evolutionary Anthropology, Leipzig, Germany

4 German Center for Integrative Biodiversity Research (iDiv), Halle-Jena-Leipzig, Germany 